\title{
Damage Control Surgery for Abdominal Trauma
}

\author{
Col R Chaudhry, vsm, Col GL Tiwari, vsm ${ }^{+}$, Surg Vice Adm Y Singh, vsm ${ }^{*}$
}

\begin{abstract}
Damage control is not a modern concept, but the application of this approach represents a new paradigm in surgery, borne out of a need to save patients with severe exsanguinating injuries. Definitive control and repair may be accomplished in the immediate post injury setting but the physiological derangement due to massive shock state resulting from the severe injury and the resuscitation that follows, often leads to a fully repaired but dead patient. The vicious triad of death in trauma, namely hypothermia, acidosis and coagulopathy should be tackled by initial abbreviated laparotomy, correction of physiological derangements and finally definitive repair of all injuries at second laparotomy. The concept needs a dedicated team effort with careful patient selection for achieving the optimal results.
\end{abstract}

MJAFI 2006; 62 : 259-262

Key Words: Damage control surgery; hypothermia; acidosis; coagulopathy

\section{Introduction}

$\mathrm{M}$ ajor advances have taken place in the management of trauma patients in the last two decades. Advances in pre-hospital care and resuscitation have enabled the early survival of many injured patients. Another shift is the change in the spectrum of severity of injury, characterised by high energy blunt and penetrating abdominal trauma resulting in severe multiorgan injuries. What followed was predictable - trauma surgeons went for complete repair of complex injuries. Patients died of metabolic derangements due to severe exsanguinating injuries and the resuscitative effort that followed, leading to trauma triad of death - hypothermia, coagulopathy and acidosis [1]. This expensive and frustrating exercise of managing trauma patients made the surgeons introspect and thus evolved the concept of damage control surgery in the late eighties $[2,3]$. 'Damage Control' is a term used by United States Navy that describes the capacity of a ship to absorb damage and maintain mission integrity [4]. It has become the preferred descriptor of this modern, three phased surgical approach to the catastrophically injured trauma patient $[5,6]$.

In 1983, Stone made the important transition from packing of liver injuries to packing of the exsanguinating, cold and coagulopathic trauma patients [7]. In this landmark study, 11 of the 17 patients thought to have lethal coagulopathy survived. The three phase of Damage Control were also defined. The concept was associated with high complication rate and required another ten years and multiple independent reports to establish the acceptability of the concept $[8,9,10]$. The goal of damage control is to preserve life. The triad of hypothermia, acidosis and coagulopathy once established in a patient of multiple injuries is lethal in $90 \%$ cases [11].

\section{Damage Control Approach}

Damage Control as practised today has three separate components. Phase I consists of abbreviated laparotomy for rapid control of haemorrhage and contamination. Intra abdominal packing and temporary abdominal closure, completes this critical step. The patient is then moved to the intensive care unit (ICU) where phase II of Damage Control Surgery (DCS) is executed. This consists of core re-warming, correction of coagulopathy and acidosis. Once normal physiology has been restored, re-exploration is undertaken for definitive management of injuries and abdominal closure, constituting phase III of DCS [8]. DCS encompasses this algorithm to improve patient survival.

\section{Phase I - Damage Control Surgery}

The initial surgery consists of rapid control of haemorrhage, exploration, control of contamination, definitive packing and rapid abdominal closure. Packing provides tamponade of bleeding when it is surgically unmanageable or coagulopathy is setting in. This provides a longer period of resuscitation. Bleeding vessels can be rapidly isolated, repaired, ligated or shunted, if necessary. Complex repairs and graft interposition are time consuming in cold coagulopathic patients. Control

*Prof \& Head (Dept of Surgery), AFMC, Pune-40. +Dy Commandant, ALC, Pune-40. "DGMS (Navy), Integerated HQ, Ministry of Defence (Navy). 
of contamination is by ligation, stapling or just single layer closure of perforation without wasting time in trying to establish continuity of the gut. Temporary abdominal closure to prevent abdominal hypertension can be achieved by a variety of innovative techniques like towel clip skin closure, sito bags or the more sophisticated vacuum pack. The indications for DCS have been described in six general categories viz - inability to achieve haemostasis due to coagulopathy, inaccessible major venous injury, time consuming procedure in a critically ill patient, management of extra abdominal life threatening injury, inability to close the abdomen due to visceral oedema and reassessment of intra abdominal contents. Critical variables include surgeons skill, severity of injury and other associated injuries [12]. The decision to implement DCS in a given case is a deliberate and calculated surgical approach, requiring mature surgical judgment. The classic triggers for DCS are $\mathrm{pH}<7.30$, 10 units of blood transfusion or estimated blood loss of $>4$ litres and core temperature of $35^{\circ} \mathrm{C}$ or lower. However, for optimal success, DCS should be applied early rather than late, when the fatal triad of hypothermia, coagulopathy and acidosis is well entrenched. The utility of early packing in major liver and pancreatico-duodenal injuries has now become an accepted procedure to save the patient rather than trying to do prolonged surgery [13-15].

\section{Phase II - Damage Control Surgery}

The second phase of DCS is carried out in the ICU with the intent to correct metabolic derangement within 24 to 36 hours.

Hypothermia : Heat loss begins at the moment of traumatic insult. Shock, low tissue perfusion, prolonged exposure during transport and in emergency room and immobility of acutely injured patient are some of the known causes of hypothermia. Add this to the cold resuscitation fluids given. Clinically hypothermia is considered when core temperature is less than $35^{\circ} \mathrm{C}$ and a temperature below $34^{\circ} \mathrm{C}$ carries significant mortality [16]. Hypothermia has a global detrimental effect on the coagulation cascade leading to coagulopathy [17]. Multiple methods aimed at limiting and reversing hypothermia have been described. These include active and passive external re-warming by keeping ambient temperature at $27^{\circ} \mathrm{C}$, warming lights and warm air blankets. Active core re-warming can be achieved by using warmed ventilator gases and intravenous fluids and heated pleural lavage. Extra corporeal re-warming techniques using an arteriovenous circuit can be used though this may be limited by need for anticoagulation. Continuous arterio-venous rewarming rapidly increases the core temperature by non-shivering thermogenesis [18]. Inability to rewarm a patient correlates with increased morbidity and mortality. It suggests that patient may have ongoing bleeding.

Coagulopathy : Every aspect of the normal clotting mechanism is affected in a cold acidotic exsanguinated patient. Dilution of coagulation factors and platelets by fluid resuscitation, decreased total and ionised calcium concentration and hypothermia all contribute to coagulopathy. Hypothermia leads to dysfunction of intrinsic and extrinsic coagulation pathways [18]. Inhibition of the enzymatic reactions of these pathways is demonstrated by prolongation of prothrombin and partial thromboplastin times. However coagulation testing is normally performed at $37^{\circ} \mathrm{C}$ rather than at patients core temperature and may underestimate the degree of coagulopathy $[19,20]$. Platelet dysfunction in hypothermia leads to prolonged bleeding time. Changes in enzyme kinetics affected by temperature may also delay the initiation and propagation of platelet aggregation, despite adequate replacement of platelet number, hence the need for correction of hypothermia. In addition there is poor correlation between platelet count and continued bleeding and in these settings there is justification for platelet transfusion even with a 'normal' platelet count [21]. Increased fibrinolytic activity and imbalance in production and degradation of fibrin may also lead to excessive bleeding [22]. Thromboelastography can broadly determine coagulation abnormalities and give information about fibrinolytic activity and platelet function. It is of practical utility in managing coagulopathy in DCS [23].

Acidosis : Acidosis associated with hypovolaemic shock contributes to coagulopathic bleeding, which worsens the shock state. Control of haemorrhage and optimal delivery of oxygen is the key to correction of acidosis. This is achieved by blood transfusion and augmentation of cardiac output. Persistence of metabolic acidosis as reflected by lack of clearance of serum lactate levels within 48 hours, is a strong predictor of mortality [24].

Interventional Radiological Techniques : The use of interventional radiological techniques have added to the success of DCS. These procedures can control bleeding in difficult and inaccessible locations [25, 26]. In a recent study Kushimoto et al, showed that interventional angiography is the treatment of choice for managing retroperitoneal haematoma that is nonexpanding and inaccessible in patients with coagulopathy [27].

\section{Intra abdominal Hypertension and Abdominal Compartment Syndrome}

Abdominal Compartment Syndrome (ACS) is a lethal complication of severe abdominal trauma. Raised intra 
abdominal pressure in abdominal trauma is due to massive transfusion and crystalloid infusion resulting in intestinal oedema, continuing intra abdominal bleeding, intra abdominal packing, light skin or facial closure and ileus. Currently there is no agreed definition of ACS but values above $20 \mathrm{~mm}$ of $\mathrm{Hg}$ are considered abnormal in most [28]. Abdominal hypertension leads to respiratory compromise, decreased cardiac output and renal failure. The most widely used method of measuring intra abdominal pressure is measurement of bladder pressure via a transurethral catheter. This correlates well with intra abdominal pressure $[29,30]$. The treatment of abdominal hypertension is urgent laparotomy and temporary abdominal closure techniques. Although no absolute guidelines exist, the triggers for re-exploration are abdominal pressure $>20 \mathrm{~mm} \mathrm{Hg}$ with a urine output $<0.5 \mathrm{ml} / \mathrm{kg} /$ hour, peak airway pressure $>45 \mathrm{~cm} \mathrm{H}_{2} \mathrm{O}$ or $>26 \mathrm{~mm} \mathrm{Hg}$ of intra abdominal pressure [31].

\section{Phase III-Damage Control Surgery}

Once the patient's haemodynamic status has been stabilised, hypothermia, acidosis and coagulopathy corrected, the patient is taken for planned re-exploration. This should be accomplished between 24-48 hours of initial packing, to decrease the subsequent intra abdominal infective complications like abscess formation and gut fistulisation [10]. At re-exploration thorough search for missed injuries is made, repacking is rarely required and formal abdominal closure can be undertaken if visceral oedema has subsided [12]. Other than planned re-exploration some patients may need early surgery for ongoing haemorrhage ( $>4$ unit blood transfusion), abdominal hypertension or uncontrolled contamination [32].

\section{Complications of Damage Control Surgery}

Considering the nature of injury and the physiological status of patients undergoing DCS, it is not surprising that the complications and mortality is high. Complications include wound infection rate of 50-100\%, intra abdominal abscess $25-8 \%$, enterocutaneous fistula $20-25 \%$ and abdominal hypertension in $20 \%$ patients. The mortality ranges from $12-67 \%$ in various studies [33-36]. In view of this, it is essential that the trauma surgeon must follow the recommended guidelines for application of DCS. Use of principles of DCS at the right time will save the life of critically ill trauma patients [37]. Regardless of the increased morbidity, the principles of damage control are here to stay, and in fact are being extended to orthopaedic and thoracic trauma [38,39].

In conclusion, DCS has evolved over the last two decades as a concept in the management of patients with exsanguinating abdominal injuries. It is neither a bailout procedure nor an abandonment of proper surgical technique. It is a deliberate and calculated surgical approach requiring mature surgical judgment. It has been shown to reduce mortality rates significantly when applied to injuries that were previously not survivable. However, further studies are required for better definition of indications of DCS.

\section{Conflicts of Interest}

None identified

\section{References}

1. Kashuk JL, Moore EE, Millikan JS, Moore JB. Major abdominal vascular trauma: a unified approach. J Trauma 1982; 22: 672-9.

2. McGonial MD. Urban firearm deaths : a five years perspective. J Trauma 1993; 35: 532-40.

3. Feliciano DV, Burch JM, Spjut-Partinely VRN, Mattox KL, Jordan Jr GL. Abdominal gun shot wounds. Ann Surg 1988; 208: 362-70.

4. Department of Defence. Surface Ship Survivability. Naval Warfare Publication 3-20.31. Washington DC: US Government Printing Office, November 1996.

5. Peninga L, Peninga EI, Swendson LB. Damage Control Surgery in multiply traumatised patients. Ugeska Laegar 2005; 167 : 3403-7.

6. Scalea TM. Damage control for torso trauma. Hosp Med 2005; 66: 84-7.

7. Stone HH, Strom PR, Mullins RJ. Management of the major coagulopathy with onset during laparotomy. Ann Surg 1983; 197: 532-5.

8. Rotondo MF, Schwab CW, McGonial MD, Philips GR, Fruchterman TM, Kaudar DR. 'Damage Control': An approach to improved survival in exsanguinating penetrating abdominal injury. J Trauma 1993; 35: 375-83.

9. Sharp KW, Locicero RJ. Abdominal packing for surgically uncontrollable haemorrhage. Ann Surg 1992; 215: 467-75.

10. Hischberg A, Wall MJ, Mattox KL. Planned reoperation for trauma: a two year experience with 124 consecutive patients. J Trauma 1994; 37: 365-9.

11. Ferrara A, MacArther J, Wright H. Hypothermia and acidosis worsen coagulopathy, in the patient receiving massive transfusion. Am J Surg 1990; 160: 515-8.

12. Shaprio MB, Jenkins DH, Schwab CW, Rotondo MF. Damage Control: Collective Review. J Trauma 2000; 49: 969-78.

13. Fengjun L, Mteta KA, Yutring Z, Nanhai S. Complex therapy for hepatic trauma. East Afr Med J 2005; 82: 28-33.

14. MacKenzie S, Kortbeck JB, Mulloy R, Hameed SM. Recent experience with multidisciplinary approach to complex hepatic trauma. Injury 2004; 35: 869-77.

15. Rickmand MJ, Brohi K, Bautz PC. Pancreatic and duodenal injury: keep it simple. ANZ J Surg 2005; 75: 581-6.

16. Jurkovich GJ, Greiser WB, Luterman A, Curreri PW. Hypothermia in trauma victims. An ominous predictor of survival. J Trauma 1987; 27: 1019-24.

17. Rohrer MJ, Natale AN. Effect of hypothermia on coagulation cascade. Crit Care Med 1992; 20: 1402-5.

18. Genitello L, Rifley W. Continuous arteriovenous rewarming: report of a new technique for treating hypothermia. J Trauma 
1991: 31: 1151-4.

19. Gubler K, Gentilello L, Hassntash S. The impact of hypothermia on dilutional coagulopathy. J Trauma 1994; 36 : 847-51.

20. Reed R, Bracey A, Hodson J. Hypothermia and blood coagulation: dissociation between enzyme activity and clotting levels. Circ Shock 1990; 32: 141-52.

21. Boldt J, Menges T, Wlobruck M. Platelet function in critically ill patients. Chest 1994; 106: 899-903.

22. Enderson B, Chen J, Robinson R. Fibrinolysis in multi-system trauma patients. J Trauma 1991; 31: 1240-6.

23. Kaufmann CR, Dwyer KM, Crews JD. Usefulness of thromboelastography in assessment of trauma patient coagulation. J Trauma 1997; 42: 716-22.

24. Abramson D, Scalea TM, Hitchcock R, Trooskin SZ, Henry SM, Greenspam J. Lactate clearance and survival following injury. J Trauma 1993; 35: 584-9.

25. Hoffer EK, Borsa JJ, Bloch RD, Fontaine AB. Endovascular techniques in damage control setting. Imaging Symp 1999; 19: 1340-8.

26. DeToma G, Mingoli A, Modini C, Cavallaro A, Stipa S. The value of angiography and selective hepatic artery embolisation for continuous bleeding after surgery in liver trauma; case reports. J Trauma 1994; 37: 508-11.

27. Kushimoto S, Arai M, Aiboshi J, Harada N, et al. The role of interventional radiology in patients requiring damage control surgery. J Trauma 2003; 54: 171-6.

28. Moore AFK, Hargest R, Martin M, Delicata RJ. Damage Control in the abdomen and beyond. Br J Surg 2004; 91: 1102-10.

29. Kron IL, Harman PK, Nolan SP. The measurement of intra abdominal pressure as a criterion for abdominal re-exploration. Ann Surg 1984; 199: 28-30.
30. Yol S, Kartal A, Tavli S, Tarkan Y. Is urinary bladder pressure a sensitive indicator of intra-abdominal pressure? Endoscopy 1998; 30: 778-80.

31. Meldrum DR, Moore FA, Moore EE, Franciose RJ, Sauaia A, Burch JM. Prospective characterisation and selective management of abdominal compartment syndrome. Am J Surg 1997; 174: 667-73.

32. Cue J, Cryer H, Miller F. Packing and planned re-exploration for hepatic and retroperitoneal haemorrhage: critical refinement of a useful technique. J Trauma 1990; 30: 1007-13.

33. Rotondo MF, Zonies DH. The damage control sequence and underlying logic. Surg Clin North Am 1997; 77: 761-77.

34. Morris J, Eddy V, Blinman T. The staged celiotomy for trauma: issues in unpacking and reconstruction. Ann Surg 1993; 217: 576-86.

35. Garrison J, Richardson D, Hilakos A. Predicting the need to pack early for severe intra abdominal haemorrhage. J Trauma 1996; 40: 923-9.

36. Saggi BH, Sugermann HJ, Ivatury RR, Bloomfield GL. Abdominal compartment syndrome. J Trauma 1998; 45: 597-609.

37. Nicholas JM, Rix EP, Easely KA, Felciano DV, et al. Changing patterns in the management of penetrating abdominal trauma: the more things change the more they remain the same. J Trauma 2003; 55: 1095-110.

38. Roberts CS, Pape HC, Jones AS, Malkam AL, Rodriguez AL, Ginnoudis PV. Damage Control Orthopaedics: evolving concepts in treatment of patients who have sustained orthopaedic trauma. Instr Course Lect 2005; 54: 447-62.

39. Cacres M, Buechter KJ, Tillou A, Smith JA, Liu D, Stub G. Thoracic packing for uncontrolled bleeding in penetrating thoracic injury. South Med J 2004; 97: 637-41. 